\title{
COVID-19 during pregnancy one year on — what lessons did we learn?
}

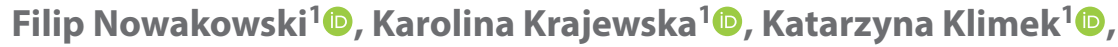 \\ Waldemar Wierzba ${ }^{2,3}$, Artur Jacek Jakimiuk ${ }^{1,4}$ \\ ${ }^{1}$ Department of Obstetrics and Gynecology, Central Clinical Hospital of Interior, Warsaw, Poland \\ ${ }^{2}$ Central Clinical Hospital MSWiA, Warsaw, Poland \\ ${ }^{3}$ University of Humanities and Economics in Lodz, UHE Satellite Campus in Warsaw, Poland \\ ${ }^{4}$ Center of Reproductive Health, Institute of Mother and Child, Warsaw, Poland
}

\begin{abstract}
It is now more than a year since the first case of Severe Acute Respiratory Syndrome Coronavirus 2 (SARS-CoV-2) disease (COVID-19) was diagnosed in China. Current data suggest that pregnancy may not only be a risk factor for the development of severe forms of COVID-19, but that the SARS-CoV-2 infection may impact on common pregnancy complications as well. Healthy pregnant women are likely to be more susceptible to viral infection and therefore are at higher risk of developing severe COVID-19 because of adaptive changes in their immune and respiratory systems, their altered endothelial cell functions, and modified coagulation responses. However, studies show that most pregnant women diagnosed with COVID-19 developed mild-to-moderate symptoms and only a few of them have required critical care facilities. In contrast with preeclampsia, preeclampsia-like syndrome can resolve spontaneously following recovery from severe pneumonia and may not be an obstetric indication for delivery. Preeclampsia-like syndrome is one symptom of COVID-19, but its cause is different from obstetric preeclampsia and therefore not connected with placental failure. Vertical transmission of SARS-CoV-2 infection is rare but can probably occur. No evidence has been found that COVID-19 developed during pregnancy leads to unfavourable outcomes in the fetus. Most health authorities indicate that standard procedures should be used when managing pregnancy complications in asymptomatic women with confirmed SARS-CoV-2. Vaccines should not be withheld from pregnant and lactating individuals who otherwise meet the vaccination criteria.
\end{abstract}

Key words: COVID-19; pregnancy; SARS-CoV-2; vaccination

Ginekologia Polska 2021; 92, 5: 383-386

\section{INTRODUCTION}

It is now more than a year since the first case of Severe Acute Respiratory Syndrome Coronavirus 2 (SARS-CoV-2) disease (COVID-19) was diagnosed in China. As of 14 March 2021 there have been over 120.3 million cases and about 2.6 million deaths reported globally since the start of the pandemic [1]. In Poland by the same date, there had been 1.9 million confirmed cases of COVID-19 and 47,178 deaths [2]. As the numbers of COVID-19 cases, hospitalizations, and deaths all continue to rise across the world, it is paramount for clinicians to be up to date with the most recent information on the course and treatment of this novel disease. By reviewing the most recent studies on maternal and fetal outcomes among COVID-19 diagnosed women from around the world, our study seeks to determine whether pregnant women are more likely to develop severe forms of COVID compared with non-pregnant women, and whether pregnant women affected by COVID during pregnancy are more likely to develop common obstetric complications, such as preterm birth, preeclampsia, caesarean section, and others. We will also make clinical recommendations based on our analysis of the literature.

\section{SUSCEPTIBILITY TO SARS-COV-2 DURING PREGNANCY AND SYMPTOMS OF COVID-19 AMONG PREGNANT WOMEN}

According to data published over the past year, healthy pregnant women are likely to be more susceptible to SARS-CoV-2 infection than non-pregnant women. This is

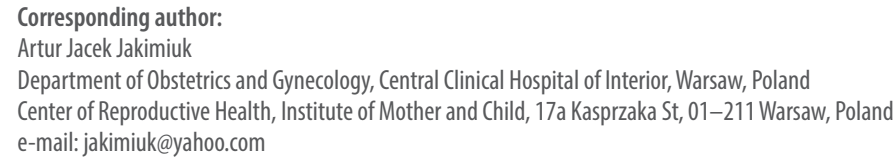


most probably due to adaptive changes in the woman's immune system during pregnancy, resulting in altered immune responses to infections during pregnancy [3-5]. In addition, there are several anatomical changes that take place in the pregnant woman's respiratory system. A reduction in chest volume leads to decreased functional residual capacity, end-expiratory volumes, and residual volumes. These further result in a reduction of total lung capacity and an inability to clear secretions. These are the most significant factors that can make pregnant women more-than-otherwise susceptible to severe respiratory infections, including Coronavirus disease 2019 (COVID-19) [6]. Another important issue is the possibility of additive or synergistic risk factors for thrombosis in pregnant women affected with COVID-19. It is already established that COVID-19 is associated with high rates of thromboembolic complications [7]. Due to various changes in the coagulation response during pregnancy, which include increased thrombin production, increased intravascular inflammation and higher levels of plasminogen, pregnant women are at an increased risk of thromboembolic events [8,9]. In light of the above, current guidelines suggest that all pregnant woman diagnosed with COVID-19 should have thromboprophylaxis postnatally until the $10^{\text {th }}$ day [10].

Emerging evidence suggests that endothelial cell dysfunction plays a significant role in the onset and progression of acute respiratory distress syndrome [11], which is the main cause of mortality in COVID-19 [12-14]. Endothelial cell dysfunction is also observed in women with preeclampsia [15]. These data may suggest that this group is at a higher risk of developing severe COVID-19 [16].

\section{IMPACT OF SARS-COV-2 ON PREGNANCY}

Since January 2020, several studies have described the presentation and clinical course of COVID-19 in pregnancy. Up till now it appears that pregnant women are not at an increased risk of developing severe COVID-19 [17]. Wastnedge et al., reviewed data from 31 studies with quite reassuring results. Of more than 12,000 pregnant women with COVID-19 diagnosed, the majority developed mild to moderate symptoms, and only few women required critical care facilities. In the same review, the authors found that overall, 146 deaths had been reported. Severe complications of COVID-19 during pregnancy are rare but these can occur. Pre-existing comorbidities, advanced maternal age, and high body mass index seem to be risk factors for severe COVID-19 [18]. Based on the collected data, less than $10 \%$ of infected pregnant women required admission to an intensive care unit [19]. Most of those admitted to ICU suffered from pneumonia, acute respiratory distress syndrome (ARDS), or multiple organ dysfunction syndrome (MODS) [20-22].

\section{COVID-19 AND HYPERTENSIVE DISORDERS IN PREGNANCY}

Hypertensive disorders are the most common medical complications of pregnancy and a major cause of maternal and perinatal morbidity and death. Detecting elevated blood pressure during pregnancy is one of the cardinal aspects of optimal antenatal care. With the outbreak of novel coronavirus-19 disease important is to check all COVID-19 diagnosed pregnant women for hypertensive disorders [7].

Mendoza et al. [23], carried out an observational study in which they found some features of preeclampsia (PE) in women with COVID-19 infection. Although there is a variant pathomechanism between actual preeclampsia and preeclampsia connected with SARS-CoV-2, it can be difficult to differentiate based on clinical symptoms. Detailed laboratory assessment, including angiogenic factors can be helpful in distinguishing between the two conditions. PE-like syndrome, in contrast to preeclampsia, can resolve spontaneously after recovery from severe pneumonia and may not be an obstetric indication for delivery. PE-like syndrome is a symptom of COVID-19, and not connected with placental failure.

\section{VERTICAL TRANSMISSION OF SARS-COV-2}

Among studies that include neonatal test results for SARS-CoV-2, only a few of them report COVID-19 positive cases $[7,24,25]$. It remains unclear whether infection occurs in utero, or during labour, or at birth as the tests have mostly used polymerase chain reaction (PCR)-based methods. More evidence is required on this subject, especially in terms of routine PCR and antibody testing in neonates.

\section{EFFECTS OF VIRAL INFECTION ON THE FETUS}

In the majority of the studies reporting on neonatal outcomes, no serious adverse outcomes in the neonates born to SARS-CoV-2 positive mothers have been observed [17]. Available data comparing the neonatal outcomes in a group of symptomatic COVID-19 mothers with those of symptomatic non-COVID-19 mothers, found no significant differences in the rates of adverse neonatal outcomes [26].

\section{MEDICAL HEALTH AUTHORITY GUIDELINES}

The American College of Obstetricians and Gynaecologists (ACOG), the Royal College of Obstetricians and Gynaecologists (RCOG) and the Polish Society of Gynaecologists and Obstetricians (PTGiP) recommend testing all pregnant women admitted to hospital, and not only those with COVID-19 symptoms, due to the asymptomatic course of the disease. Treatment of typical diseases during pregnancy in asymptomatic patients with COVID-19 should be carried out using standard procedures. However, if a patient has 
dyspnoea, fever, a deterioration in their general condition, they may require some or all of these additional treatments: oxygen therapy, antibiotics, steroid therapy, and thromboprophylaxis. Mode of delivery will depend on obstetric indications. COVID-19 is not an indication for caesarean section itself unless the symptoms of COVID-19 cause the woman's condition to deteriorate $[27,28]$.

According to most medical health authorities, including the World Health Organization (WHO), RCOG, ACOG, and the Centers for Disease Control and Prevention (CDC), COVID-19 is not a contraindication for breastfeeding, which is recommended for all women who wish to breastfeed. Up till now, there is no evidence of serious adverse events in neonates, therefore patients with confirmed SARS-CoV-2 infection should be encouraged to continue breastfeeding, while taking adequate precautions to prevent transmission of the virus to the baby [27-29]. According to the Polish Neonatal Society, and the National Perinatology Consultant in accord with the National Infectious Diseases Consultant, breastfeeding is recommended to all women who wish to breastfeed. It is only contraindicated when the general condition of the mother or the baby requires medical assistance. The decision to breastfeed is left to the mother following a documented written informed consent process has been completed prior to childbirth, where the possible risks and benefits of breastfeeding for the neonate as well as the negative impact of isolation on the mother are made clear [30].

\section{Vaccination in pregnant women}

Specific clinical trials of COVID-19 vaccines in pregnant women have not yet been carried out. Worldwide, there are numerous discrepancies between local guidelines regarding the safety of COVID-19 vaccines during pregnancy. According to the ACOG, COVID-19 vaccines should not be withheld from pregnant and lactating individuals who meet the criteria for vaccination based on the Advisory Committee on Immunization Practices (ACIP) [28]. According to the RCOG, vaccination can be discussed with pregnant and / or breastfeeding women if they are clinically in an extremely vulnerable group or if they are frontline health or social care workers, including working in a residential care facility [27, 31]. In Poland, the PTGiP emphasises that pregnant women with active COVID-19 are burdened with a higher risk of severe disease but the authority has not yet released a statement about vaccination [32]. According to the Danish Health Authority, pregnant or breastfeeding women will not be offered vaccination. However, in exceptional cases, for example in the presence of severe chronic diseases, a pregnant woman may be offered a vaccination based on an individual medical assessment [33]. According to the Health Service Executive in Ireland (HSE), pregnant and breastfeeding women should receive a COVID-19 vaccine when it is available to them; and the first dose should be given no sooner than 14 gestational weeks, and the second dose should be given before the end of 34 weeks of gestation [34]. The Swiss Bundesamt für Gesundheit (BAG) and Belgium's Superior Health Council do not recommend COVID-19 vaccination for pregnant women. Only those women with specific chronic diseases should be considered on a case-by-case basis $[35,36]$. The most recent data presented by Mullins et al., based on a group of 4,005 pregnant women with either suspected or confirmed SARS-CoV-2 infection, has indicated the need for enhanced precautions to prevent SARS-CoV-2 infection in pregnancy, particularly in the context of the increased risks of preterm delivery and maternal mortality, and the need for priority vaccination of women planning pregnancy [37].

\section{SUMMARY}

Scientists are constantly expanding our understanding of COVID-19. Due to relative lack of experience with the novel disease, both pregnant women and obstetricians all around the world became anxious about the impact of SARS-CoV-2 infection on pregnancy outcomes. The above review is reassuring, showing that in most pregnant women, COVID-19 is not likely to become a severe life-threatening condition, neither for the mother nor for the neonate. The most recent treatment recommendations include the safest procedures for pregnant women, mothers, and their children immediately following delivery.

There are still many unknowns that require further study. Firstly, any mechanism of vertical transmission should be identified if such exists. In addition, it is paramount to discover whether infection during pregnancy is likely to lead to any long-term adverse effects in offspring, and whether such effects are dependent on gestational age at time of infection. Therefore, a database of all infected pregnant woman should be established and made available for further investigations and follow-up studies.

Finally, scientists should be urged to include pregnant women in the clinical trials of new treatment methods and prophylaxis in order to establish the safety of these methods for this particular group.

\section{Conflicts of interest}

The authors declare no conflict of interest.

\section{REFERENCES}

1. https://www worldometers info/coronavirus (2021-03-16).

2. https://www worldometers info/coronavirus/country/poland (202103-16).

3. Li $X$, Zhou J, Fang $M$, et al. Pregnancy immune tolerance at the maternal-fetal interface. Int Rev Immunol. 2020; 39(6): 247-263, doi: 10.1080/08830185.2020.1777292, indexed in Pubmed: 32530719.

4. Silasi M, Cardenas I, Kwon JY, et al. Viral infections during pregnancy. Am J Reprod Immunol. 2015; 73(3): 199-213, doi: 10.1111/aji.12355, indexed in Pubmed: 25582523. 
5. Phoswa WN, Khaliq OP. Is pregnancy a risk factor of COVID-19? Eur J Obstet Gynecol Reprod Biol. 2020; 252: 605-609, doi: 10.1016/j. ejogrb.2020.06.058, indexed in Pubmed: 32620513.

6. GoodnightWH, Soper DE. Pneumonia in pregnancy. Crit Care Med. 2005; 33(10 Suppl): S390-S397, doi: 10.1097/01.ccm.0000182483.24836.66, indexed in Pubmed: 16215363.

7. Knight M, Bunch K, Vousden N, et al. UK Obstetric Surveillance System SARS-CoV-2 Infection in Pregnancy Collaborative Group. Characteristics and outcomes of pregnant women admitted to hospital with confirmed SARS-CoV-2 infection in UK: national population based cohort study. BMJ. 2020; 369: m2107, doi: 10.1136/bmj.m2107, indexed in Pubmed: 32513659.

8. Di Renzo GC, Giardina I. Coronavirus disease 2019 in pregnancy: consider thromboembolic disorders and thromboprophylaxis. Am J Obstet Gynecol. 2020; 223(1): 135, doi: 10.1016/j.ajog.2020.04.017, indexed in Pubmed: 32333857.

9. Ji HL, Zhao R, Matalon S, et al. Elevated plasmin(ogen) as a common risk factor for COVID-19 susceptibility. Physiol Rev. 2020; 100(3): 1065-1075, doi: 10.1152/physrev.00013.2020, indexed in Pubmed: 32216698.

10. Poon LC, Yang H, Kapur A, et al. Global interim guidance on coronavirus disease 2019 (COVID-19) during pregnancy and puerperium from FIGO and allied partners: Information for healthcare professionals. Int J Gynaecol Obstet. 2020; 149(3): 273-286, doi: 10.1002/ijgo.13156, indexed in Pubmed: 32248521.

11. Bowman ZS, Eller AG, Bardsley TR, et al. Risk factors for placenta accreta: a large prospective cohort. Am J Perinatol. 2014; 31(9): 799-804, doi: 10.1055/s-0033-1361833, indexed in Pubmed: 24338130.

12. Wu Z, McGoogan JM. Characteristics of and important lessons from the coronavirus disease 2019 (COVID-19) outbreak in China: summary of a report of 72314 cases from the chinese center for disease control and prevention. JAMA. 2020; 323(13): 1239-1242, doi: 10.1001/jama.2020.2648, indexed in Pubmed: 32091533.

13. Teuwen LA, Geldhof V, Pasut A, et al. COVID-19: the vasculature unleashed. Nat Rev Immunol. 2020; 20(7): 389-391, doi: 10.1038/s41577020-0343-0, indexed in Pubmed: 32439870.

14. Varga $Z$, Flammer AJ, Steiger $P$, et al. Endothelial cell infection and endotheliitis in COVID-19. Lancet. 2020; 395(10234): 1417-1418, doi: 10.1016/S0140-6736(20)30937-5, indexed in Pubmed: 32325026.

15. Burton GJ, Redman CW, Roberts JM, et al. Pre-eclampsia: pathophysiology and clinical implications. BMJ. 2019; 366: I2381, doi: 10.1136/bmj. I2381, indexed in Pubmed: 31307997.

16. Di Mascio D, Khalil A, Saccone G, et al. Outcome of coronavirus spectrum infections (SARS, MERS, COVID-19) during pregnancy: a systematic review and meta-analysis. Am J Obstet Gynecol MFM. 2020; 2(2): 100107 , doi: 10.1016/j.ajogmf.2020.100107, indexed in Pubmed: 32292902.

17. Wastnedge EAN, Reynolds RM, van Boeckel SR, et al. Pregnancy and COVID-19. Physiol Rev. 2021; 101(1): 303-318, doi: 10.1152/physrev.00024.2020, indexed in Pubmed: 32969772.

18. Allotey J, Stallings $\mathrm{E}$, Bonet $\mathrm{M}$, et al. for PregCOV-19 Living Systematic Review Consortium. Clinical manifestations, risk factors, and maternal and perinatal outcomes of coronavirus disease 2019 in pregnancy: living systematic review and meta-analysis. BMJ. 2020; 370: m3320, doi: 10.1136/bmj.m3320, indexed in Pubmed: 32873575.

19. Atshan SS, Hamat RA, Coolen MJL, et al. The role of subinhibitory concentrations of daptomycin and tigecycline in modulating virulence in staphylococcus aureus. Antibiotics (Basel). 2021; 10(1): 39, doi: 10.3390/antibiotics10010039, indexed in Pubmed: 33401579.

20. Ellington $S$, Strid $P$, Tong VT, et al. Characteristics of women of reproductive age with laboratory-confirmed SARS-CoV-2 infection by pregnancy status - United States, January 22-June 7, 2020. MMWR Morb Mortal Wkly Rep. 2020; 69(25): 769-775, doi: 10.15585/mmwr.mm6925a1, indexed in Pubmed: 32584795.
21. Breslin N, Baptiste C, Miller R, et al. Coronavirus disease 2019 in pregnancy: early lessons. Am J Obstet Gynecol MFM. 2020; 2(2): 100111, doi: 10.1016/j.ajogmf.2020.100111, indexed in Pubmed: 32518902.

22. Zaigham $M$, Andersson $O$. Maternal and perinatal outcomes with COVID-19: a systematic review of 108 pregnancies. Acta Obstet Gynecol Scand. 2020; 99(7): 823-829, doi: 10.1111/aogs.13867, indexed in Pubmed: 32259279.

23. Mendoza M, Garcia-Ruiz I, Maiz N, et al. Pre-eclampsia-like syndrome induced by severe COVID-19: a prospective observational study. BJOG. 2020; 127(11): 1374-1380, doi: 10.1111/1471-0528.16339, indexed in Pubmed: 32479682.

24. Ferrazzi E, Frigerio L, Savasi V, et al. Vaginal delivery in SARS-CoV-2-infected pregnant women in Northern Italy: a retrospective analysis. BJOG. 2020; 127(9): 1116-1121, doi: 10.1111/1471-0528.16278, indexed in Pubmed: 32339382.

25. Zamaniyan M, Ebadi A, Aghajanpoor S, et al. Preterm delivery, maternal death, and vertical transmission in a pregnant woman with COVID-19 infection. Prenat Diagn. 2020; 40(13): 1759-1761, doi: 10.1002/pd.5713, indexed in Pubmed: 32304114.

26. Yang H, Sun G, Tang F, et al. Clinical features and outcomes of pregnant women suspected of coronavirus disease 2019. J Infect. 2020; 81(1): e40-e44, doi: 10.1016/j.jinf.2020.04.003, indexed in Pubmed: 32294503.

27. Royal College of Obstetricians and Gynaecologists. Coronavirus [COVID-19] infection in pregnancy. https://www.rcog.org.uk/en/guidelines-research-services/guidelines/coronavirus-pregnancy/2020 (202103-16).

28. American College of Obstetricians and Gynecologists' Immunization ID, and Public Health Preparedness Expert Work Group. General Information Regarding Pregnant Individuals and COVID-19. https://www. acog.org/en/Clinical/Clinical\%20Guidance/Practice\%20Advisory/Articles/2020/03/Novel\%20Coronavirus\%2020192020 (2021-03-16).

29. World Health Organization. https://www.who.int/news-room/commentaries/detail/breastfeeding-and-covid-19 (2021-03-16).

30. Konsultant krajowy w dziedzinie neonatologii; Prezes Polskiego Towarzystwa Neonatologicznego. Zalecenia dotyczące sposobu postępowania w związku z aktualną sytuacją epidemiologiczną w przypadku noworodków matek zakażonych lub z podejrzeniem COVID-19. https://www.gov. pl > attachment (2021-03-16)

31. Royal College of Obstetricians and Gynaecologists. Updated advice on COVID-19 vaccination in pregnancy and women who are breastfeeding. https://www.rcog.org.uk/en/news/updated-advice-on-covid-19-vaccination-in-pregnancy-and-women-who-are-breastfeeding/ (2021-03-16).

32. Polskie Towarzystwo Ginekologów i Położników. http://usgptgip. pl/2021/01/14/ciaza-a-szczepienie-przeciwko-covid-19/2021 (202103-16).

33. Danish Health Authority. https://www.sst.dk/en/English/publications/2021/Vaccination-against-COVID-19---pamphlet (2021-01-18).

34. Health Service Executive Ireland. https://www2.hse.ie/screening-and-vaccinations/covid-19-vaccine/covid-19-vaccine-and-pregnancy.html (2021-01-29).

35. Recommendations for vaccinating pregnant women, women wishing to conceive and breastfeeding mothers against SARS-CoV-2 using an MRNA vaccine. https://www.health.belgium.be/sites/default/files/uploads/fields/fpshealth_theme_file/20210126_shc_9622_covid-19_vaccination_pregnant_woman_breastfeeding_vweb.pdf (2021-03-16).

36. https://foph-coronavirus.ch/downloads/downloads-covid-19-vaccine/ (2021-03-16).

37. Mullins $\mathrm{E}$, Hudak M, Banerjee J, et al. Pregnancy and neonatal outcomes of COVID-19 - co-reporting of common outcomes from the PAN-COVID and AAP SONPM registry. Ultrasound Obstet Gynecol. 2021; 57(4): 573-581, doi: 10.1002/uog.23619, indexed in Pubmed: 33620113. 